RECURSOS HUMANOS 


\title{
RELAÇÃO ENTRE ASPECTOS DE MODERNIDADE ORGANIZACIONAL E COMPROMETIMENTO ORGANIZACIONAL
}

\author{
RELATIONSHIP BETWEEN ORGANIZATIONAL MODERNITY AND \\ ORGANIZATIONAL COMMITMENT
}

Vanessa Machado Arraes

Universidade Federal do Ceará

Augusto Cézar de Aquino Cabral

Universidade Federal do Ceará

Sandra Maria dos Santos

Universidade Federal do Ceará

Maria Naiula Monteiro da Silva

Universidade Federal do Ceará
Emanuel Dheison dos Santos Penha Universidade Federal do Ceará

Data de submissão: 21 abr. 20|6. Data de aprovação: 05 dez. 2016. Sistema de avaliação: Double blind review. Universidade FUMEC / FACE. Prof. Dr. Henrique Cordeiro Martins. Prof. Dr. Cid Gonçalves Filho.

\section{RESUMO}

Este estudo tem por objetivo investigar a relação entre a modernidade organizacional e o comprometimento organizacional em empregados públicos das Sociedades de Economia Mista do Ceará. O trabalho foi baseado na abordagem de padrões de modernidade organizacional, propostos por Eboli (1996) nos moldes validados por Sant'Anna (2002) e na abordagem tridimensional de comprometimento organizacional proposta por Meyer, Allen e Smith (1993). Recorreu-se a análise fatorial exploratória e confirmatória para a validação das escalas e ao modelo de equações estruturais para a confirmação das hipóteses. A população da pesquisa foi composta por 479 empregados, tendo como amostra 339 respondentes. Numa avaliação geral, a modernidade das organizações foi classificada como moderada. $O \mathrm{com}$ prometimento afetivo e o normativo foram avaliados como altos, e o instrumental como moderado. Foi possível constatar, ainda, por meio da modelagem de equações estruturais uma relação positiva e significativa entre a modernidade organizacional e o comprometimento afetivo e normativo.

\section{PALAVRAS-CHAVE}

Modernidade Organizacional. Comprometimento Organizacional. Empregados públicos. Gestão de Recursos Humanos. Sociedade de Economia Mista. 


\section{ABSTRACT}

This study aimed to investigate the relationship between organizational modernity and organizational commitment to public officials of joint capital company of Ceará. This paper was based on organizational patterns modern approach proposed by Eboli (1996) along the lines validated by St. Anna (2002) and organizational commitment dimensional approach proposed by Meyer, Allen and Smith (1993). It conducted exploratory and confirmatory factor analysis to validate the scales and structural equation model for the confirmation of hypotheses. The research population was comprised of 479 employees, and a sample of 339 respondents. A general evaluation, modernity organizations was classified as moderate. Affective commitment and normative were assessed as high, and the instrumental as moderate. It was found, also through structural equation modeling a positive and significant relationship between organizational modernity and the affective and normative commitment.

\section{KEYWORDS}

Organizational Modernity. Organizational Commitment. Public Employees. Human Resource Management. Joint Capital Company

\section{INTRODUÇÃO}

A questão da modernidade vem sendo abordada sob diversas perspectivas, vindo a incitar debates sociológicos, filosóficos, políticos, econômicos e também de gestão. Eboli (1996) atribui que a modernidade é um processo dinâmico e complexo que traz como cerne a multidimensionalidade, indo além da utilização de novas tecnologias de última geração, buscando sustentação em outros aspectos e estratégias de gestão que não se prenda apenas ao racionalismo econômico.

Tomando como base o atributo da multidimensionalidade, a definição de estratégias para modernizar as organizações, tanto públicas como privadas, deve considerar os aspectos culturais, sociais, políticos, econômicos e tecnológicos que as permeiam, de modo a possibilitar o envolvimento do capital humano e dos recursos necessários para a consecução dos objetivos organizacionais.

Observando o cenário dinâmico e o ambiente competitivo do mundo atual, Dutra e Hipólito (2012) enfatizam que devido à exigência de um processo contínuo de desenvolvimento das organizações houve uma transformação do contrato psicológico entre as organizações e as pessoas, requerendo um aporte maior de comprometimento por parte do colaborador, que nem sempre é tão explicito e percebido quanto aos fatores que os suscitam.

Segundo Zanelli e Silva (2008) o comprometimento também está diretamente ligado à maturidade, a busca de autonomia e a satisfação com o conteúdo do trabalho, fazendo com que o indivíduo passe a estabelecer objetivos e assumir a respon- 
sabilidade por seus próprios comportamentos. Os autores ressaltam ainda que o comprometimento não é obtido por meio de imposição, relações de obediência ou do simples contato do indivíduo com a organização.

Assim, a organização pode vir a facilitar ou dificultar o processo de desenvolvimento do comprometimento. Sá e Lemoine (1998) constataram, em pesquisa sobre os efeitos do estilo de liderança no comprometimento organizacional, que as organizações com modelo de gestão gerencial, em contraponto ao modelo burocrático, respondem melhor a construção de uma identificação positiva do funcionário com a organização.

Custódio et al. (20l3) afirmam que uma gestão que adota práticas orientadas para resultados, que enaltece a participação e a comunicação entre os trabalhadores e o líder, propicia o enriquecimento das tarefas e entre outras ações tende a instigar de forma positiva a satisfação e o comprometimento do trabalhador.

Partindo desse pressuposto, a adoção de políticas e práticas de gestão modernas que envolvam e estimulem um maior grau de comprometimento dos colaboradores para com as organizações deve ser vista não só como propulsoras do desempenho, mas também como estratégias para manter e atrair as pessoas com competência na organização, levando em consideração que a valorização do capital humano nas organizações é um fator essencial para o alcance do sucesso organizacional.

Estes aspectos também são imprescindíveis na administração pública, especialmente quando o Estado atua como pessoa jurídica de direito privado, com atuação no domínio econômico, seja prestando ser- viço público ou exercendo atividade de exploração econômica, como no caso das sociedades de economia mista, caracterizadas como sociedades anônimas.

Tais organizações recebem, portanto, influencias dos dois setores, visto que ao mesmo tempo em que conferem aos empregados públicos, selecionados por meio de concurso público, uma maior estabilidade em comparação as organizações do setor privado, precisam estabelecer mecanismos de retê-los e comprometê-los de modo a manterem-se competitivas.

Diante desse contexto, este estudo tem como propósito investigar a relação entre o grau de modernidade organizacional e o grau de comprometimento organizacional sob a perspectiva dos empregados públicos das Sociedades de Economia Mista do Governo do Estado do Ceará. Para tanto, têm-se como objetivos específicos: aferir o grau de modernidade de cada dimensão, identificando a mais desenvolvida; aferir o grau de comprometimento de cada dimensão, identificando a mais desenvolvida; propor um modelo relacional entre modernidade organizacional e comprometimento organizacional e analisar a relação entre as dimensões de modernidade organizacional e de comprometimento organizacional.

Como referencial teórico para consecução dessa pesquisa, fez-se uso, em especial, da abordagem de padrões de modernidade organizacional, proposta por Eboli (1996) nos moldes validados por Sant'Anna (2002), no que diz respeito à modernidade administrativa e de gestão de pessoas, modernidade cultural e modernidade política, além da abordagem de comprometimento organizacional proposta por Meyer, Allen e Smith (1993), validado no Brasil por Medeiros e Enders (1998), envolvendo as três di- 
mensões: afetiva, instrumental e normativa.

Para o alcance dos objetivos propostos, a pesquisa de natureza quantitativa e descritiva, usou como instrumento de coleta de dados um questionário aplicado com os empregados públicos de quatro Sociedades de Economia Mista do Governo do Estado do Ceará, e para a análise dos dados foi realizada técnicas descritivas e multivariadas.

Além desta introdução, quatro seções compõem este trabalho. $A$ seção 2 relata a revisão de literatura relacionada à modernidade organizacional e ao comprometimento organizacional. A seção 3 apresenta a metodologia do trabalho. Os resultados são abordados e analisados na seção 4. Por fim, as considerações finais do trabalho são apresentadas na última seção.

\section{REVISÃO DA LITERATURA}

Esta seção discorre sobre modernidade organizacional e comprometimento organizacional, conceitos determinantes para o atingimento dos objetivos dessa pesquisa.

\section{Modernidade organizacional}

A busca da modernidade nas organizações aponta para o processo estratégico de enfrentar as mudanças decorrentes dos aspectos sociais, econômicos e políticos, necessários a manutenção da competitividade nos novos padrões mundiais, requerendo a adoção de modelos estruturais, estratégias, políticas e práticas de gestão que propiciem a formação de conteúdos culturais que permitam $\circ$ desenvolvimento de comportamentos condizentes com essa nova realidade (DEL MAESTRO FILHO, 2004).

Segundo Giddens (2002), as instituições modernas se distinguem das outras formas de instituição devido ao dinamismo e ao grau que interferem nos hábitos e costu- mes tradicionais. Para o autor, "uma das características distintivas da modernidade, de fato, é a crescente interconexão entre dois extremos da extensão e da intencionalidade: influências globalizantes de um lado e disposições pessoais de outro" (GlDDENS, 2002, p. 9).

$O$ autor afirma, ainda, que na modernidade o futuro é constantemente trazido para $\circ$ presente e que o seu dinamismo requer a separação de tempo e espaço, mecanismos de desencaixe e reflexividade institucional através dos ambientes de conhecimento.

Trazendo a visão da realidade brasileira e atendo-se aos padrões de competição da configuração global que as organizações enfrentam em todo mundo, Eboli (1996) analisou a questão da modernidade de forma mais abrangente, contrapondo-se ao conceito de modernidade usual, imediatista e reducionista, com foco apenas em suas dimensões mais visíveis e tangíveis, como a prosperidade econômica ou a disponibilidade e utilização de tecnologias de ponta.

Desta forma, em seu estudo sobre a modernidade na gestão de bancos, a autora consolidou os principais atributos da modernidade, enquanto um processo dialético, complexo e multidimensional tendo o sujeito como o elo de interação e articulação com seis dimensões de modernidade: cultural, política, social, administrativa, econômica e tecnológica.

Diante deste aparato teórico-conceitual, Eboli (1996) elaborou indicadores de modernidade organizacional, com o intuito de avaliar de forma mais completa a modernidade na gestão empresarial e entender objetivamente como esse processo se dá no contexto organizacional, abrangendo 
as seis dimensões da sociedade moderna citadas acima, que posteriormente foram agrupados e validados, por meio de análise estatística multivariada, por Sant'Anna (2002) em seu estudo sobre a relação das competências individuais, a modernidade organizacional e a satisfação no trabalho, resultando nas três dimensões de modernidade apresentadas no Quadro I.

\section{Comprometimento organizacional}

A literatura internacional sobre comprometimento organizacional ( $\mathrm{CO}$ ) iniciou na metade da década de 70 e durante os anos 80 cresceu significativamente (BORGES-ANDRADE, 1994). No Brasil, Medeiros et al (2003) informam que os estudos sobre CO iniciaram-se em meados da década de 1990, sendo bastante explorados desde então.

\section{QUADRO 1 - Dimensões e indicadores de modernidade organizacional.}

\begin{tabular}{|c|c|}
\hline Dimensão & Escala de Modernidade Organizacional \\
\hline \multirow{4}{*}{$\begin{array}{l}\text { Modernidade } \\
\text { Cultural }\end{array}$} & 1- A organização encoraja a iniciativa e responsabilidade individual \\
\hline & $\begin{array}{l}\text { 2- O clima interno da organização estimula que as pessoas estejam em continuo processo de } \\
\text { aprendizagem no seu dia-a-dia de trabalho }\end{array}$ \\
\hline & 3- O clima interno da organização estimula ideias novas e criativas \\
\hline & 4- Na organização há um clima estimulante para que as pessoas realizem atividades, buscando se superar \\
\hline \multirow{7}{*}{$\begin{array}{l}\text { Modernidade } \\
\text { Política }\end{array}$} & 5- Os processos de tomada de decisão são participativos e transparentes. \\
\hline & $\begin{array}{l}\text { 6- No que se refere ao aspecto político, o regime que vigora na organização pode ser caracterizado como } \\
\text { democrático. }\end{array}$ \\
\hline & 7- O Processo decisório na organização é descentralizado. \\
\hline & 8- A organização favorece a autonomia para tomar decisões \\
\hline & $\begin{array}{l}\text { 9- A organização conta com sistemas de gestão participativos que estimulam a iniciativa e ação das } \\
\text { pessoas }\end{array}$ \\
\hline & 10- A organização admite a diversidade de comportamentos e respeita as diferenças individuais \\
\hline & $\begin{array}{l}\text { 11- O ambiente de trabalho facilita o relacionamento entre as pessoas, mesmo de níveis hierárquicos } \\
\text { diferentes. }\end{array}$ \\
\hline \multirow{12}{*}{$\begin{array}{c}\text { Modernidade } \\
\text { Administrativa } \\
\text { e de Gestão de } \\
\text { Pessoas }\end{array}$} & 12- A estratégia, missão, objetivos e metas da organização são claramente definidos. \\
\hline & $\begin{array}{l}\text { 13- De modo geral, os empregados sabem o que devem fazer para colaborar com os objetivos da } \\
\text { organização. }\end{array}$ \\
\hline & $\begin{array}{l}\text { 14- As políticas e práticas de recursos humanos da organização estimulam o desenvolvimento pessoal e } \\
\text { profissional. }\end{array}$ \\
\hline & 15- Os principais critérios para promoção são a competência e a produtividade da pessoa. \\
\hline & 16- Há um sistema de avaliação que permite diferenciar o bom e o mau desempenho. \\
\hline & 17- O sistema de remuneração da organização recompensa os atos de competência. \\
\hline & $\begin{array}{l}\text { 18- As políticas e práticas de recursos humanos estimulam as pessoas a se preocuparem com a } \\
\text { aprendizagem contínua. }\end{array}$ \\
\hline & 19- A organização é fortemente orientada para resultados. \\
\hline & $\begin{array}{l}\text { 20- A organização equilibra adequadamente a preocupação com resultados financeiros, com as pessoas e } \\
\text { com a inovação. }\end{array}$ \\
\hline & $\begin{array}{l}\text { 21- A organização combina, de forma equilibrada, a utilização de tecnologias avançadas com a criatividade } \\
\text { das pessoas. }\end{array}$ \\
\hline & 22- A tecnologia empregada favorece a interação entre pessoas e áreas. \\
\hline & $\begin{array}{l}\text { 23- As políticas e práticas da organização estimulam que as pessoas estejam sempre bem informadas e } \\
\text { atualizadas. }\end{array}$ \\
\hline
\end{tabular}

Fonte: Sant'Anna (2002, p.190) 
Para Rego (2003), devido ao atual ambiente competitivo, as organizações precisam de pessoas que vão além das suas funções formais, que sejam comprometidas em dar respostas rápidas, criativas e inovadoras a problemas inéditos. Nos estudos sobre CO "presume-se que as pessoas mais comprometidas têm maiores probabilidades de permanecerem na organização e de se empenharem na realização de seu trabalho e no alcance dos objetivos organizacionais" (REGO, 2003, p. 26). Por isso, esse tema é tão relevante para as organizações.

Para Mowday, Steers e Porter (1979) o comprometimento organizacional é um constructo amplo que reflete uma resposta geral do indivíduo à organização como um todo, podendo ser caracterizado por um forte desejo de adesão à organização, estando disposto a exercer um esforço considerável em benefício da mesma, e uma forte aceitação dos objetivos e valores da organização. Borges-Andrade (1994, p. 38) busca sintetizar $\mathrm{CO}$ ao defini-lo como o "vestir a camisa da organização".

Siqueira e Gomide Jr. (2004) declaram que o $\mathrm{CO}$ se refere ao relacionamento de uma pessoa com outra, com um grupo ou organização. Tal relacionamento é caracterizado por uma interação social com base em uma obrigação ou promessa entre as partes. Bandeira, Marques e Veiga (2000) retratam $\mathrm{CO}$ como um forte vínculo do empregado com a organização, que o incita a dar energia e lealdade à organização. Para Meyer e Herscovitch (200I), CO é uma força que liga um indivíduo a um curso de ação para um alvo relevante, que pode ser dividido em diferentes dimensões desempenhando um papel na formação do comportamento.

Meyer e Allen (199I) declaram que CO pode ser definido como sentimentos ou crenças sobre a relação do empregado com a organização refletindo um desejo (afetivo), uma necessidade (instrumental) ou obrigação (normativo) de manter a participação na organização. Esses autores discorrem que, embora haja muitas e variadas definições de $\mathrm{CO}$, elas refletem, pelo menos, esses três temas gerais.

Ao analisar as definições de CO, Bastos (1993), González e Guillén (2008), Meyer e Allen (1991) e Bandeira, Marques e Veiga (2000) declaram que não há consenso quanto ao significado do termo comprometimento. A definição também sofre de problemas conceituais que, associado aos métodos tradicionais dessa pesquisa, causam não correspondência dos resultados às expectativas dos pesquisadores (BASTOS, 1993). Meyer e Allen (199I) defendem ainda que o problema foi agravado pelo uso de medidas de comprometimento as quais nem sempre correspondem às definições. Já Bandeira, Marques e Veiga (2000) enfatizam que todas as propostas de estudos de CO partem da premissa de o vínculo do indivíduo com a organização ser inevitável e que altos níveis de comprometimento trazem resultados benéficos para a organização e seus membros.

Seguindo os preceitos da multidimensionalidade do comprometimento organizacional, Meyer e Allen ( 1991 ), em seus estudos, observaram que o mesmo decorre de um estado psicológico que caracteriza a relação do trabalhador com a organização, influenciando na decisão de permanência nesta, mas este estado não se origina apenas de um aspecto ou fator, e o reconhecimento dessas diferenças foram apontadas pelos autores como os três componentes do comprometimento, sendo eles: o comprometimento evidenciado como um ape- 
go à organização, sendo denominado como comprometimento afetivo; o comprometimento associado aos custos de sair da organização, definido como comprometimento instrumental; e o comprometimento percebido como uma obrigação em permanecer na organização, descrito como comprometimento normativo (MEYER; ALLEN; SMITH, 1993).

Meyer eAllen (I99|) argumentaram que a utilização do termo componente, em vez de tipos de comprometimento, era mais adequada, considerando que a relação do indivíduo não se restringe apenas a um componente, podendo o mesmo indivíduo apresentar graus diferentes de todos os três componentes, daí a importância de estudá-lo como um constructo multidimensional, ou seja, para o alcance de uma compreensão mais clara da relação de um empregado com a organização, os pesquisadores devem considerar a influência dos três componentes.

Para mensurar os componentes elencados, Meyer e Allen (I99I) desenvolveram as escalas de comprometimento afetivo, instrumental e normativo, posteriormente modificada em 1993 por Meyer, Allen e Smith (1993), passando a ser uma das mais utilizadas no mundo. No Brasil, o modelo modificado pelos autores em 1993 foi validado por Medeiros e Enders (1998), que confirmou a estrutura tridimensional do comprometimento e o seu poder de generalização por meio da análise fatorial, conforme apresentado no Quadro 2.

Diante da literatura abordada, as hipóteses aqui lançadas têm como propósito fundamental cumprir o objetivo desse trabalho, tendo como constructo a relação

\section{QUADRO 2 - Escala de Comprometimento organizacional}

\begin{tabular}{|c|c|}
\hline Dimensão & Escala de Comprometimento Organizacional \\
\hline \multirow{6}{*}{$\begin{array}{l}\text { Comprometimento } \\
\text { Afetivo }\end{array}$} & 1- Eu seria muito feliz em dedicar o resto de minha carreira nesta organização. \\
\hline & 2- Eu realmente sinto os problemas da organização como se fossem meus. \\
\hline & 3- Eu não sinto, em mim, um forte senso de integração com esta organização. \\
\hline & 4- Eu não me sinto emocionalmente vinculado a esta organização. \\
\hline & 5- Eu não me sinto como uma pessoa de casa nesta organização. \\
\hline & 6- Esta organização tem um imenso significado pessoal para mim. \\
\hline \multirow{6}{*}{$\begin{array}{l}\text { Comprometimento } \\
\text { Instrumental }\end{array}$} & 7- Na situação atual, ficar nesta organização é, na realidade, uma necessidade mais do que um desejo. \\
\hline & 8- Mesmo que eu quisesse, seria muito difícil para eu deixar esta organização agora. \\
\hline & 9- Se eu decidisse deixar esta organização agora, minha vida ficaria bastante desestruturada. \\
\hline & 10- Eu acho que teria poucas alternativas se deixasse esta organização. \\
\hline & $\begin{array}{l}\text { 11- Se eu já não tivesse dado tanto de mim nesta organização, eu poderia pensar em trabalhar num } \\
\text { outro lugar. }\end{array}$ \\
\hline & $\begin{array}{l}\text { 12- Uma das poucas consequências negativas de deixar esta organização seria a escassez de } \\
\text { alternativas imediatas. }\end{array}$ \\
\hline \multirow{6}{*}{$\begin{array}{l}\text { Comprometimento } \\
\text { Normativo }\end{array}$} & 13- Eu não sinto nenhuma obrigação de permanecer nesta organização. \\
\hline & 14- Mesmo se fosse vantagem para mim, sinto que não seria certo deixar esta organização agora. \\
\hline & 15- Eu me sentiria culpado se deixasse esta organização agora. \\
\hline & 16- Esta organização merece minha lealdade. \\
\hline & 17- Eu não deixaria esta organização agora, porque tenho uma obrigação moral com as pessoas daqui. \\
\hline & 18- Eu devo muito a esta organização. \\
\hline
\end{tabular}

Fonte: Meyer, Allen e Smith (1993) adaptado de Medeiros e Enders (1998). 
entre a modernidade organizacional e o comprometimento organizacional, para tanto formulou-se o modelo hipotético da pesquisa, conforme a representação esquemática apresentada na Figura I.

H.I Existe correlação positiva entre a modernidade organizacional (MOD) e o comprometimento organizacional (CO).

H.O (nula) não existe correlação positiva entre a modernidade organizacional (MOD) e o comprometimento organizacional (CO).

Desta forma, o intuito do modelo busca analisar se com a adoção de políticas e práticas de gestão modernas tem alguma inter-relação que possa vir a facilitar ou dificultar o processo de desenvolvimento do comprometimento para com a organização.

\section{METODOLOGIA}

Quanto aos aspectos metodológicos, essa pesquisa é quantitativa, pois se propõe a analisar, a partir das variáveis que compõe as dimensões de modernidade organizacional e as dimensões de comprometimento, a relação existente entre os dois constructos, conforme preconiza Roesch (2006).
Quanto aos objetivos ou fins, a pesquisa se caracteriza como descritiva visto que pretende relacionar as variáveis às questões ou hipóteses específicas. Segundo Gil (2008) a pesquisa descritiva refere-se à descrição das características de determinada população ou fenômeno, estabelecendo relações entre variáveis.

Para tanto, foi aplicada uma survey, que segundo Babbie (2005) é um método de pesquisa que visa à exploração ou à descrição de determinado fenômeno. Como instrumento de pesquisa utilizou-se um questionário, composto pelo perfil demográfico e funcional dos respondentes, a escala de modernidade organizacional validada por Sant'Anna e a escala reduzida do modelo tridimensional de Meyer, Allen e Smith (1993), validada no Brasil por Medeiros e Enders (1998), sendo a coleta de dados realizada tanto in loco, como por meio da ferramenta limesurvey, respeitando o critério de acessibilidade indicado pela organização.

A população da pesquisa foi composta por 479 empregados públicos, de quatro Sociedades de economia mista do Estado

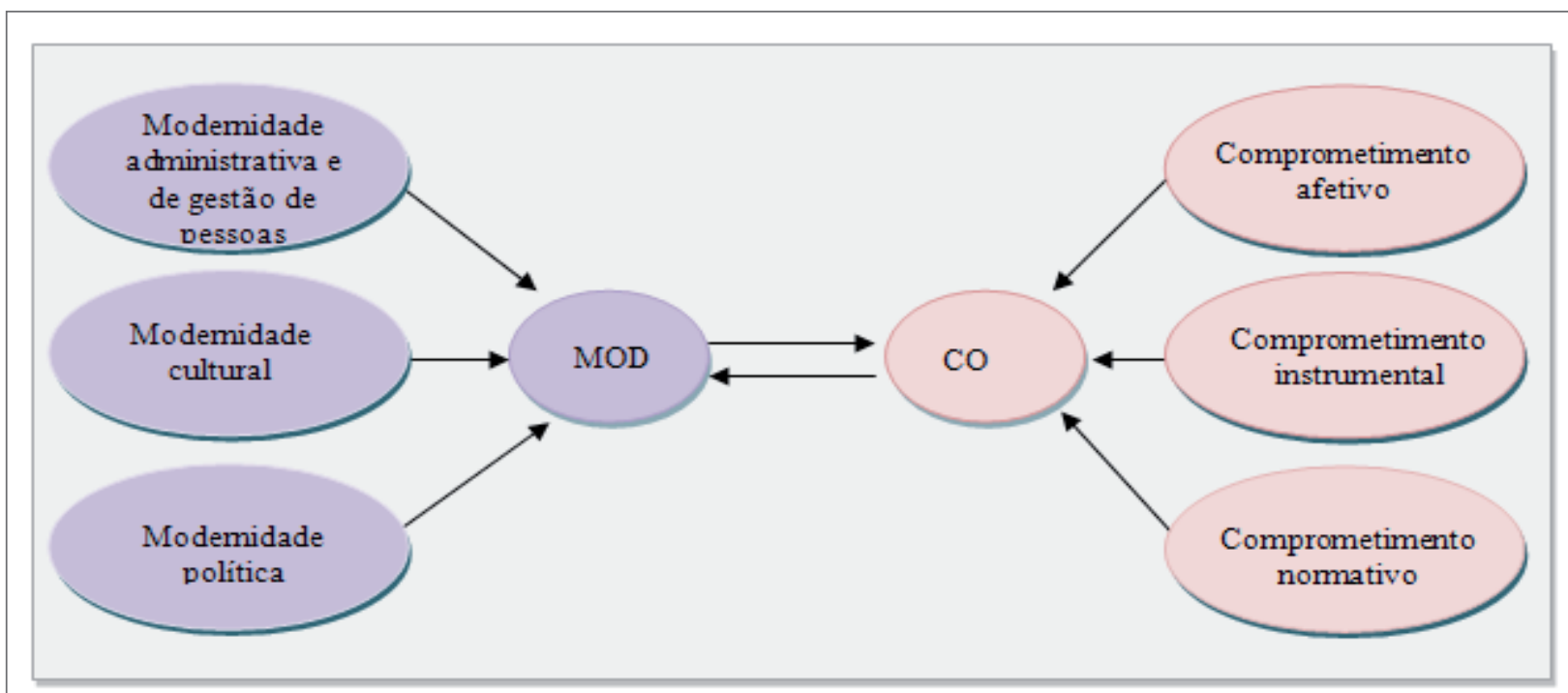

FIGURA 1 - Modelo hipotético inicial proposto para a pesquisa

Fonte: Elaborado pelos autores. 
do Ceará, que trabalham nas sedes dessas organizações, excluindo-se os que trabaIham em campo ou em sedes regionalizadas, tendo como amostra 339 respondentes, que, após a retirada dos outliers, se resumiram a 324 respondentes.

Para alcançar o objetivo deste estudo, inicialmente, foram codificados todos os questionários e consolidadas as respostas da pesquisa, utilizando para tratamento estatístico os softwares Statistical Package for Social Sciences (SPSS) e Analysis of Moment Structures (AMOS).

Após a tabulação dos dados, realizou-se a análise exploratória com a finalidade de analisar os dados ausentes, para os quais atribuiu-se como critério a substituição pela média, conforme recomendado por Hair et al. (2009).

A análise descritiva dos indicadores de modernidade organizacional toma como parâmetro à média, o desvio padrão e coeficiente de variação (CV). Além disto, o Quadro 3, baseando-se nos parâmetros do estudo de Del Maestro Filho (2004) para avaliar o grau de modernidade organizacio- nal, foi elaborada com a finalidade de estabelecer os intervalos adotados para classificar o grau de modernidade organizacional, levando em consideração a orientação da escala Likert utilizada no instrumento de pesquisa (que quanto mais próximo a 10 for o escore, maior a concordância).

Para os indicadores de comprometimento organizacional também se utilizou como análise descritiva a média, o desvio padrão e coeficiente de variação (CV). $O$ Quadro 4 elenca os intervalos adotados para classificar o grau de comprometimento organizacional, observando a orientação da escala Likert utilizada no instrumento de pesquisa (que quanto mais próximo a 5 for o escore, maior a concordância).

As variáveis de modernidade organizacional e de comprometimento organizacional foram tratadas estatisticamente por meio de aplicação de técnicas de análise multivariadas, tais com: a análise fatorial exploratória (AFE), análise fatorial confirmatória (AFC), e modelos de equações estruturais - Structural Equations Modeling (SEM). Hair Jr. et al. (2009) afirmam a análise

QUADRO 3 - Avaliação do grau de modernidade organizacional.

\begin{tabular}{|c|c|c|}
\hline Escore da Escala Likert & Significado & Classificação do Grau \\
\hline 0,0 ------ 2,0 & Muito baixa concordância & Muito baixo \\
\hline 2,1 ------- 4,0 & Baixa concordância \\
\hline 4,1 ------ 6,0 & Concordância moderada & Moderado \\
\hline 6,1 -------- 8,0 & Alta concordância & Alto \\
\hline 8,1 ------- 10,0 & Muito alta concordância & Muito Alto \\
\hline
\end{tabular}

Fonte: elaborado pelos autores da pesquisa, baseado em Del Maestro Filho (2004).

QUADRO 4 - Avaliação do grau de comprometimento organizacional

\begin{tabular}{|c|c|c|}
\hline Escore da Escala Likert & Significado & Classificação do Grau \\
\hline 0,0 -------- 1,0 & Muito baixa concordância & Muito baixo \\
\hline 1,1 -------- 2,0 & Baixa concordância & Moderado \\
\hline 2,1 -------- 3,0 & Concordância moderada & Alto \\
\hline 3,1 -------- 4,0 & Alta concordância & Muito Alto \\
\hline 4,1 -------- 5,0 & Muito alta concordância & \\
\hline
\end{tabular}

Fonte: elaborado pelos autores da pesquisa. 
fatorial exploratória (AFE) é uma técnica estatística multivariada que busca a identificação da inter-relação entre variáveis, formando fatores ou dimensões. $\mathrm{Na}$ realização da AFE dessa pesquisa, foi realizado o teste de esfericidade de Bartlett, que deve ter um $p$ menor que 0,05 , e o teste KaiserMeyer-Olkin, que deve ter um valor maior que 0,5 . Foi verificada também as comunalidades, que devem ser maiores que 0,5, e as cargas fatoriais, que não devem ter diferenças menores que 0,15 entre as cargas de diferente fatores (WORTHINGTON; WHITTAKER, 2006).

$A$ análise fatorial confirmatória (AFC) permite verificar se as variáveis medidas representam os constructos fundamentados teoricamente, ou seja, trata-se de uma técnica estatística confirmatória da teoria de mensuração específica representada por um modelo teórico, sendo a primeira parte de um teste de modelo estrutural (HAIR et al., 2009). Na AFC foi verificada a validade convergente, medida através da variância extraída média (VEM) e deve ser superior a 0,5; a validade fatorial, verificada quando os pesos fatoriais forem superiores que 0,5 ; a validade discriminante, que é verificada através da comparação da VEM dos fatores com o quadrado das suas correlações, a VEM deve ser maior que o quadrado da correlação; e a confiabilidade compósita, que deve ser maior que 0,7. Também foi verificado os índices de ajustamento e modificação para analisar e readequar o modelo.

\section{ANALISE DOS RESULTADOS}

Esta seção apresenta a análise dos resultados da pesquisa, contemplando a análise descritiva dos dados, considerando a amostra final com a retirada dos outliers, e os indicadores de modernidade organizacional e de comprometimento organizacional validados após as análises fatoriais exploratória e confirmatória e a construção do modelo de equações estruturais.

\section{Análise Descritiva}

Quanto ao perfil demográfico dos respondentes foram analisados dados relativos à faixa etária, ao gênero, à escolaridade e ao estado civil. No que diz respeito à faixa etária, evidenciou-se que a maioria dos empregados públicos se encontra com idade entre 3 I e 40 anos, 39,80\% da amostra. Há predominância do sexo masculino, $55,90 \%$ dos respondentes, sobre o feminino, 44,10\%. Já em relação ao estado civil, há maior concentração de pessoas casadas: $64,80 \%$ dos respondentes são casados.

Quanto à escolaridade, observa-se que a maioria dos respondentes apresenta especialização, com representatividade de $35,80 \%$ da amostra. Em um contexto geral, constata-se um bom nível de escolaridade dos respondentes, sendo a maioria graduados ou pós-graduado.

A análise dos dados funcionais abrangeu o tempo de serviço na organização, área de atuação e tempo na função atual. Desta forma, constatou-se que a maior proporção dos empregados públicos investigados, $33,60 \%$, declarou ter de 6 a 10 anos na organização e 19,80\% são recém admitidos com menos de I ano na casa. Observou-se, também, que a maioria dos respondentes da pesquisa atua na área administrativa da organização o que corresponde a $38,00 \%$, seguidos dos que atuam executando serviços mais operacionais, com 32,10\%. A representatividade da área gerencial corresponde a $22,80 \%$ e da diretoria $6,50 \%$. Salienta-se que $0,60 \%$, que corresponde a 
2 respondentes, não informaram a área de atuação na organização.

Evidenciou-se que $37,30 \%$ dos empregados públicos pesquisados estão exercendo a função atual no período comprendido entre I a 5 anos, $26,50 \%$ atuam a menos de I ano na função e $23,50 \%$ atuam na mesma função pelo período entre 6 a 10 anos.

A Tabela I apresenta as médias e os desvios-padrão das variáveis de modernidade organizacional validadas na AFE e AFC.

Para análise da Tabela I cabe ressaltar que a retirada de alguns itens que compõe a escala aplicada nas análises fatoriais implicou na renomeação das dimensões de modernidade organizacional, para modernidade administrativa (MA), modernidade de gestão de pessoas (MGP) e modernidade política (MP), fato explicado na descrição destas análises fatoriais.

Tomando como parâmetro o Quadrol, observa-se a presença de escores que variam entre moderado e alto grau de modernidade. Destaca-se que não houve uma grande dispersão das médias, tendo em vista que o coeficiente de variação ficou acima de $50 \%$ apenas para uma das variáveis de modernidade.

Dentre os indicadores, os que apresentaram maiores valores foram os da dimensão de modernidade administrativa (MA), classificados como altos, nesta ordem: (i) a estratégia, missão, objetivos e metas da organização são claramente definidos, (ii)

TABELA 1 - Média e desvio-padrão e coeficiente de variação do modelo redefinido de modernidade organizacional

\begin{tabular}{|c|c|c|c|c|c|}
\hline Variáveis & Indicadores & Média & Desvio-padrão & CV & $\begin{array}{l}\text { Modelo } \\
\text { validado }\end{array}$ \\
\hline MP1 & $\begin{array}{l}\text { Os processos de tomada de decisão são participativos e } \\
\text { transparentes. }\end{array}$ & 5,72 & 2,55 & $44,58 \%$ & MP \\
\hline MP2 & $\begin{array}{l}\text { No que se refere ao aspecto político, o regime que vigora na } \\
\text { organização pode ser caracterizado como democrático. }\end{array}$ & 5,68 & 2,48 & $43,66 \%$ & MP \\
\hline MP3 & O Processo decisório na organização é descentralizado. & 5,49 & 2,46 & $44,81 \%$ & MP \\
\hline MP4 & A organização favorece a autonomia para tomar decisões & 5,79 & 2,41 & $41,62 \%$ & MP \\
\hline MP5 & $\begin{array}{l}\text { A organização conta com sistemas de gestão participativos } \\
\text { que estimulam a iniciativa e ação das pessoas }\end{array}$ & 6,04 & 2,36 & $39,07 \%$ & MP \\
\hline MA1 & $\begin{array}{l}\text { A estratégia, missão, objetivos e metas da organização são } \\
\text { claramente definidos. }\end{array}$ & 7,98 & 2,19 & $27,39 \%$ & MA \\
\hline MA2 & $\begin{array}{l}\text { De modo geral, os empregados sabem o que devem fazer } \\
\text { para colaborar com os objetivos da organização. }\end{array}$ & 7,15 & 2,06 & $28,78 \%$ & MA \\
\hline MA5 & $\begin{array}{l}\text { Os principais critérios para promoção são a competência e a } \\
\text { produtividade da pessoa. }\end{array}$ & 5,63 & 2,61 & $46,28 \%$ & MGP \\
\hline MA6 & $\begin{array}{l}\text { Há um sistema de avaliação que permite diferenciar o bom e } \\
\text { o mau desempenho. }\end{array}$ & 5,77 & 2,49 & $43,16 \%$ & MGP \\
\hline MA7 & $\begin{array}{l}\text { O sistema de remuneração da organização recompensa os } \\
\text { atos de competência. }\end{array}$ & 5,27 & 2,71 & $51,53 \%$ & MGP \\
\hline MA8 & $\begin{array}{l}\text { As políticas e práticas de recursos humanos estimulam as } \\
\text { pessoas a se preocuparem com a aprendizagem contínua. }\end{array}$ & 6,00 & 2,33 & $38,91 \%$ & MGP \\
\hline MA9 & A organização é fortemente orientada para resultados. & 7,28 & 1,93 & $26,44 \%$ & MA \\
\hline
\end{tabular}

Escala: 0 a 10 (11 pontos)

Fonte: Dados da pesquisa. 
a organização é fortemente orientada para resultados e (iii) de modo geral, os empregados sabem o que devem fazer para colaborar com os objetivos da organização.

Este resultado evidencia que as organizações pesquisadas estão focadas nos seus objetivos, definindo e disseminando a estratégia com os colaboradores a fim de alcançar os resultados esperados, seguindo os preceitos da orientação estratégica apontada por Mintzberg et al. (2007) como essencial para se sobressair em tempos de mudanças e incertezas constantes.

No âmbito da modernidade política (MP) os indicadores apresentaram classificação moderada de modernidade, sendo os com escores mais altos: (i) a organização conta com sistemas de gestão participativos que estimulam a iniciativa e ação das pessoas e (ii) os processos de tomada de decisão são participativos e transparentes.

Apesar de ainda não se mostrarem em alto grau, tais achados indicam uma evolução da gestão no sentido de envolver as pessoas com o trabalho e com a organização, permitindo uma participação mais ativa, diferente dos achados de Sant'Anna (2002) e Maestro Del Filho (2004), cujos estudos demonstraram a prevalência de uma gestão mais centralizada e hierarquizada.

Já nos indicadores da dimensão de gestão de pessoas (MGP), também classificados como moderados, destacaram-se: (i) as políticas e práticas de recursos humanos estimulam as pessoas a se preocuparem com a aprendizagem contínua e (ii) há um sistema de avaliação que permite diferenciar o bom e o mau desempenho.

Infere-se, desta forma, que mesmo tendo alcançado um grau moderado de modernidade, as médias dessas variáveis indicam que as organizações ainda precisam apri- morar a integração entre a competência exigida e o sistema de avaliação, remuneração e recompensa.

De maneira geral, a média da MA foi 7,47, a da MP foi 5,74 e da MGP foi 5,67 e a média global do constructo foi 6,15 , classificado como moderado. $O$ que demonstra que a percepção dos empregados públicos pesquisados sobre as práticas de gestão da organização em que trabalham pode ser considerada boa.

De forma similar, a Tabela 2 apresenta a análise descritiva dos indicadores dos três fatores de comprometimento que permaneceram após a análise fatorial e a retirada dos outliers.

A análise da Tabela 2 baseia-se nos parâmetros estabelecidos no Quadro 2 no que se refere à classificação do grau de comprometimento organizacional, a variação das médias ficou entre 2,34 e 4,20 apontando um comprometimento que vai de moderado a muito alto dentre os indicadores de comprometimento.

Salienta-se que os indicadores CA3, CA4 e CA5 estão dispostos de forma negativa na escala original, mas foram pontuados inversamente na análise estatística e, portanto, estão analisados no mesmo sentido dos demais itens.

A faixa dos desvios-padrão ficou entre 0,98 e I,24 e os coeficientes de variação (CV) não ultrapassaram $50 \%$, o que implica dizer que não houve grande variação dos dados.

A dimensão afetiva foi a que apresentou escores mais altos, destacando-se: (i) eu me sinto como uma pessoa de casa nesta organização e (ii) eu me sinto emocionalmente vinculado a esta organização. $O$ que denota o vínculo afetivo dos empregados públicos para com as organizações ainda é o fator maior de comprometimento orga- 
TABELA 2 - Média e desvio-padrão e coeficiente de variação do modelo redefinido de comprometimento organizacional.

\begin{tabular}{|c|c|c|c|c|c|}
\hline Variáveis & Indicadores & Média & Desvio-padrão & CV & $\begin{array}{l}\text { Modelo } \\
\text { validado }\end{array}$ \\
\hline CA3 & $\begin{array}{l}\text { 3-Eu sinto, em mim, um forte senso de integração com esta } \\
\text { organização. }\end{array}$ & 4,03 & 1,05 & $25,97 \%$ & $\mathrm{CA}$ \\
\hline CA4 & 4-Eu me sinto emocionalmente vinculado a esta organização. & 4,13 & 1,03 & $25,04 \%$ & CA \\
\hline CA5 & 5-Eu me sinto como uma pessoa de casa nesta organização & 4,20 & 0,98 & $23,33 \%$ & $\mathrm{CA}$ \\
\hline $\mathrm{Cl} 3$ & $\begin{array}{l}\text { 9- Se eu decidisse deixar esta organização agora, minha vida } \\
\text { ficaria bastante desestruturada. }\end{array}$ & 3,32 & 1,24 & $37,34 \%$ & $\mathrm{Cl}$ \\
\hline $\mathrm{Cl} 4$ & $\begin{array}{l}\text { 10- Eu acho que teria poucas alternativas se deixasse esta } \\
\text { organização. }\end{array}$ & 2,34 & 1,16 & $49,42 \%$ & $\mathrm{Cl}$ \\
\hline $\mathrm{Cl} 6$ & $\begin{array}{l}\text { 12- Uma das poucas consequências negativas de deixar esta } \\
\text { organização seria a escassez de alternativas imediatas. }\end{array}$ & 2,44 & 1,10 & $44,95 \%$ & $\mathrm{Cl}$ \\
\hline CN2 & $\begin{array}{l}\text { 14- Mesmo se fosse vantagem para mim, sinto que não seria } \\
\text { certo deixar esta organização agora. }\end{array}$ & 3,03 & 1,21 & $39,96 \%$ & $\mathrm{CN}$ \\
\hline CN3 & 15- Eu me sentiria culpado se deixasse esta organização agora. & 2,58 & 1,21 & $46,90 \%$ & $\mathrm{CN}$ \\
\hline CN5 & $\begin{array}{l}\text { 17- Eu não deixaria esta organização agora, porque tenho uma } \\
\text { obrigação moral com as pessoas daqui. }\end{array}$ & 3,04 & 1,14 & $37,44 \%$ & $\mathrm{CN}$ \\
\hline CN6 & 18- Eu devo muito a esta organização. & 3,80 & 1,05 & $27,66 \%$ & $\mathrm{CN}$ \\
\hline
\end{tabular}

Fonte: dados da pesquisa.

nizacional, conforme constatado em estudos como o de Pinto (20II).

Já para a dimensão do comprometimento normativo os escores mais altos são: (i) eu devo muito a esta organização e (ii) mesmo se fosse vantagem para mim, sinto que não seria certo deixar esta organização agora. Tal resultado demonstra que os empregados sentem um vínculo que permeia a gratidão para com a organização que os fazem se dedicar a mesma.

Por fim, o comprometimento instrumental, em um contexto global, foi o que apresentou os escores mais baixos. Sendo, dentre os indicadores dessa dimensão, os que mais se destacaram: (i) se eu decidisse deixar esta organização agora, minha vida ficaria bastante desestruturada, (ii) uma das poucas consequências negativas de deixar esta organização seria a escassez de alternativas imediatas e (iii) eu acho que teria poucas alternativas se deixasse esta organização.

O que evidencia que o impacto de deixar a organização se faz presente em alto grau, em primeiro lugar pela avaliação do impacto da perda financeira na vida do empregado, e, posteriormente, pelo receio da falta de oportunidades no mercado de trabalho.

A média global do comprometimento afetivo foi de 4,12 , classificada como muito alta, a do comprometimento normativo foi 3,11 , classificada como moderada, e a do comprometimento instrumental foi 2,70 , considerada baixa. Não foi calculada a média geral do comprometimento organizacional, tendo em vista que ele não foi validado como um constructo de $2^{\mathrm{a}}$ ordem, fato explicado posteriormente na subseção da análise fatorial confirmatória do comprometimento organizacional.

\section{Análise dos Construtos}

A AFE da escala de modernidade organizacional evidenciou, a princípio, quatro fatores, porém, algumas variáveis tiveram que ser excluídas. As variáveis $\mathrm{MC}, \mathrm{MCl}$, 
MC2, MC3, MC4, MA3, MA4, MAI0, MAII, MAI2 e MP6 foram eliminadas por terem diferenças menores que 0,15 nos escores dos pesos fatoriais e a variável MP7 foi eliminada por ter um índice de comunalidade menor que 0,5 .

A AFE final resultou em três fatores que explicam $78,46 \%$ da variância. As variáveis apresentaram comunalidades acima de 0,5, - KMO foi de 0,916 e valor do teste de esfericidade de Bartlet foi inferior a 0,00I. Contudo, todos os itens da dimensão de modernidade cultural foram excluídos. $\mathrm{Na}$ dimensão política ficaram cinco itens e na dimensão administrativa e de gestão de pessoas houve uma divisão dos itens em dois fatores, um fator cujos itens estão mais voltados para orientação estratégica da organização e outro fator cujos itens estão relacionados com as práticas de gestão de pessoas. Fato que resultou na alteração de nomenclatura das dimensões de acordo com a consistência teórica a que os itens se referem, conforme anteriormente abordado na Tabela I.

A AFC de modernidade organizacional, apresentou cargas fatoriais maiores que 0,5 , significantes a $0,00 \mathrm{I}$ e com bons $\left(x^{2}(51)=146 ; 650 ; \quad p=, 000 ; \quad x^{2} d f=2,875\right.$; $\mathrm{CFI}=0,938 ; \mathrm{PCFI}=0,725)$ e ruins índices de ajustamento $(\mathrm{GFI}=0,877$; $\mathrm{PGFI}=0,574$; RMSEA $=0, \mathrm{I07} ; \mathrm{P}(\mathrm{rmsea}<=0.05)=0,00 \mathrm{I})$. Observou-se ainda que o modelos obteve confiabilidade composta, validade discriminante e convergente. As dimensões de modernidade apresentam correlações de magnitude elevadas e estatisticamente significativas, o que coadunando com a justificativa teórica para a existência de um fator latente de ordem hierárquica superior, ensejou a analise fatorial de $2^{\mathrm{a}}$ ordem de modernidade organizacional.
A AFE de comprometimento organizacional confirmou a existência dos três fatores, porém com a extração de sete indicadores, sendo: ClI, CN4, CA2, $\mathrm{Cl} 5$ e Cl2 por apresentarem comunalidades menores que $0,5, \mathrm{CAI}$ por ter diferenças de cargas fatoriais menores que $0,15 \mathrm{em}$ mais de um fator e finalmente CNI por estar sozinho em um fator, considerando que Marôco (2010) defende que cada fator deve ter pelo menos 3 variáveis manifestas.

A AFC de comprometimento organizacional evidenciou cargas fatoriais maiores que 0,5 e significantes a $0,00 \mathrm{I}$. Quanto aos índices de ajustamento, foram encontrados bons $\left(x^{2}(4 I)=65,678 ; p=, 000 ; x^{2} d f=2,052\right.$; $C F I=, 940 ; G F I=, 928 ; R M S E A=0,079 ; P(r-$ msea $<=0.05)=0,043)$ e ruins índices (PCFI=,668 PGFI=,540). O modelo apresentou confiabilidade composta, validade discriminante e convergente para o construto em questão.

Contudo, as correlações entre as variáveis latentes não foram altas, não definindo a especificação de fator de $2^{\mathrm{a}}$ ordem, 0 que coaduna com a perspectiva teórica de um constructo multidimensional, conforme explicado por Meyer e Allen (1997).

Para examinar e confirmar as relações que possam existir entre os constructos pesquisados, foi realizada a modelagem de equações estruturais, resultando no modelo integrado, que buscou a relação entre o constructo de modernidade organizacional e as três dimensões do comprometimento, resultando na análise de um total de 29 variáveis, sendo 7 delas variáveis latentes (VL) e 22 variáveis de medida ou indicadores (VM).

Até se chegar ao modelo final, houve a necessidade de dois ajustes. A correlação entre a trajetória de modernidade orga- 
nizacional (MOD) $\rightarrow$ comprometimento instrumental $(\mathrm{Cl})$, não se mostrou significativa e por questões de parcimônia foram retiradas do modelo, conforme aconselha Marôco (2010).

Por fim, o modelo final indicou um ajustamento bom ao se verificar seus índices: $x^{2}(4 I)=447,733 ; p=, 000 ; x^{2} d f=2,228$; $\mathrm{CFI}=, 939 ; \mathrm{PCFI}=, 8 \mathrm{I}$ 7; $\mathrm{GFI}=, 887 ; \mathrm{PGFI}=, 705$; RMSEA=0,062; $\quad P($ rmsea $<=0.05)=0,007$, com todos os pesos fatoriais estandardizados elevados e significantes, conforme expresso no Figura 2.

Com base no modelo estrutural final, observou-se que houve alterações nas duas escalas de medidas no que se refere à exclusão de alguns indicadores.

$\mathrm{Na}$ escala de modernidade foram retirados II indicadores e as dimensões do modelo aplicado foram aglutinadas em três fatores: modernidade política, modernidade administrativa e modernidade de gestão de pessoas, preservando, entretanto, a confirmação teórica de um fator latente de $2^{\mathrm{a}}$ ordem. Os indicadores da modernidade cultural não se mostraram significativos para a amostra em questão, sendo todos retirados do modelo validado neste estudo, confirmando apenas em parte os achados de Sant'Anna (2002).

Já na escala de comprometimento organizacional foram excluídos 8 indicadores, mas preservaram-se as dimensões previstas no modelo teórico de Meyer, Allen e Smith (1993), não se confirmando, porém, a formação de um fator latente de $2^{\mathrm{a}}$ ordem, fato que pode ser explicado pelo caráter multidimensional do comprometimento, chamado pelos autores de componentes, justamente para enfatizar que o mesmo

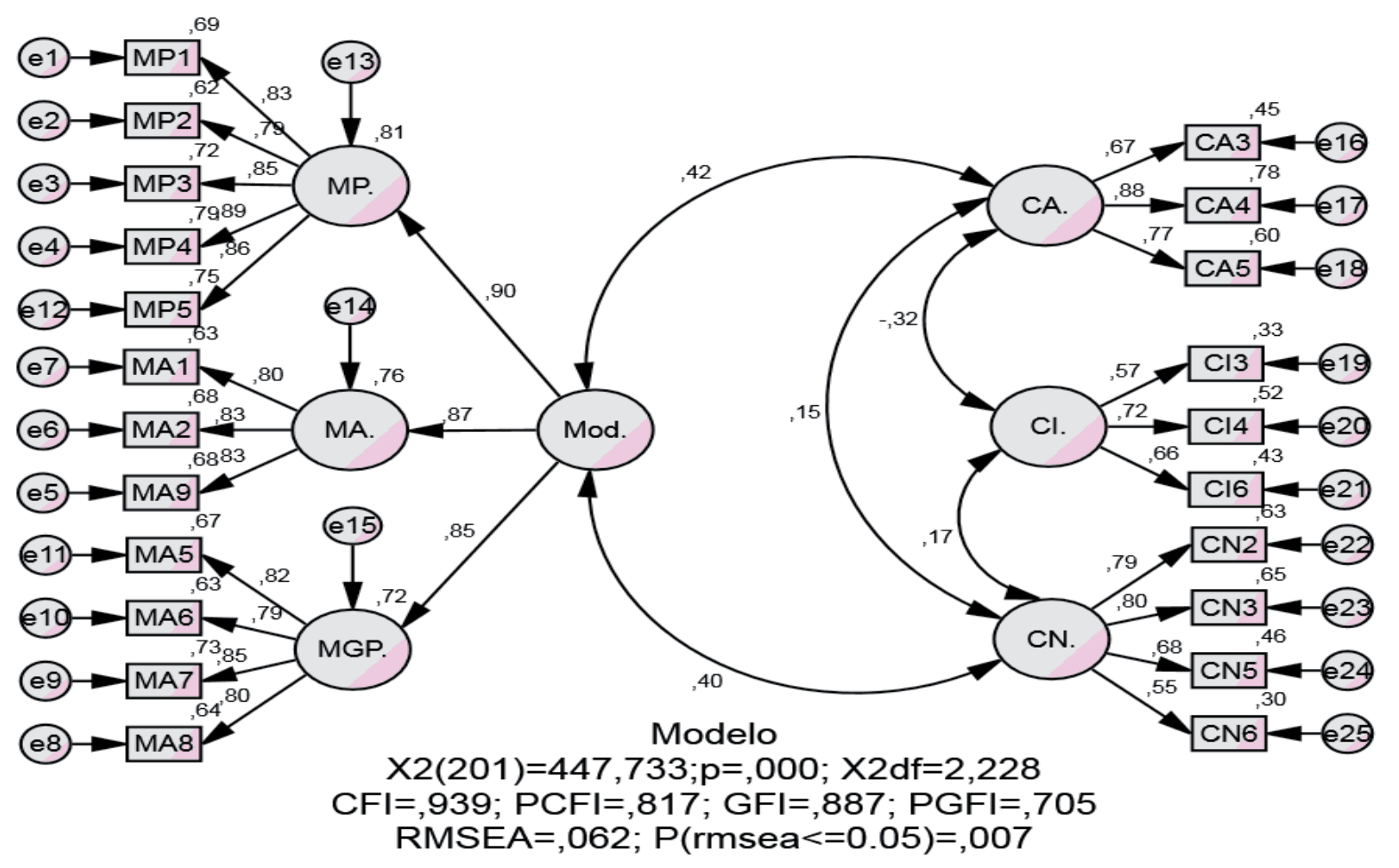

FIGURA 2 - Modelo relacional de modernidade organizacional e comprometimento.

Fonte: dados da pesquisa. 
indivíduo pode vir a se comprometer por razões diferenciadas e apresentar ou não mais de um tipo de comprometimento e em graus variados.

Diante desses achados a hipótese nula, não existe relação positiva entre a modernidade organizacional e o comprometimento organizacional, foi rejeitada e a $\mathrm{H}$.l, existe relação positiva entre a modernidade organizacional e o comprometimento organizacional, inicialmente proposta, foi parcialmente atendida, tendo em vista que, apesar de se confirmar uma correlação positiva entre a modernidade e as três dimensões de comprometimento, esta correlação só foi considerada significativa para dois dos componentes estudados, sendo eles o comprometimento afetivo e normativo.

Destaca-se, também, que há correlação entre os três componentes do comprometimento, sendo positiva entre o comprometimento afetivo e normativo e entre o comprometimento instrumental e normativo, no entanto, entre o comprometimento afetivo e instrumental mostrou-se negativa.

Indo ao encontro desta perspectiva, Ribeiro e Bastos (2010) também constataram que estas dimensões de comprometimento são autônomas e distinguíveis entre si, apresentando baixas correlações entre si, com exceção da correlação entre a dimensão afetiva e normativa que é positiva e significativa, fato também confirmado neste trabalho.

Destaca-se que as vertentes de modernidade organizacional validadas incluem no âmbito da modernidade política: a gestão participativa, a democracia e a autonomia; no âmbito da modernidade administrativa: a orientação estratégica e a gestão por resultados; e no âmbito da modernidade de gestão de pessoas: a aprendizagem contí- nua, o sistema de avaliação e a gestão por competência e remuneração.

Assim, infere-se que tais vertentes podem vir a suscitar o envolvimento do indivíduo para com a organização e, portanto, correlacionar-se com o comprometimento afetivo, de caráter atitudinal, que se origina da identificação e da internalização dos valores da organização pelo indivíduo (SIQUEIRA, 200 I) e com o comprometimento normativo, que decorre do vínculo que o indivíduo estabelece com a cultura e a estratégia da organização (RIBEIRO E BASTOS, 20I0).

Já o comprometimento instrumental está relacionado ao custo/benefício de permanecer na organização quando comparado à outra oportunidade de trabalho, conforme explica Meyer e Allen (1997), donde se infere que, dentre as dimensões de modernidade organizacional, a de gestão de pessoas seria a que mais poderia vir a despertar tal comprometimento, visto que engloba a vertente do sistema de remuneração. Porém, a correlação não se mostrou significativa.

Esses resultados corroboram com o estudo de Bandeira, Marques e Veiga (2000) sobre as dimensões múltiplas do comprometimento organizacional em uma empresa pública que também apresentou uma correlação fraca entre o comprometimento instrumental e a política salarial e menor ainda com outras práticas de recursos humanos, demonstrando que as políticas de recursos humanos têm pouca importância na manutenção deste tipo de comprometimento.

\section{Avaliação dos objetivos}

Para atender o primeiro objetivo específico de aferir o grau de modernidade de cada dimensão, identificando a mais desen- 
volvida, utilizou-se a classificação das médias em intervalos que categorizam o grau de modernidade. Desta forma, considerando a as dimensões do modelo final, verificou-se que a MA foi alta e a MGP e a MP foram classificadas como moderadas. Logo, a média global de modernidade foi classificada como moderada.

Em relação ao segundo objetivo específico de aferir o grau de comprometimento de cada dimensão, identificando a mais desenvolvida, buscou-se, também, a classificação das médias em intervalos que categorizam o grau de comprometimento. Assim, verificou-se que tanto o comprometimento afetivo, como o comprometimento normativo foram avaliados como altos, já o comprometimento instrumental foi avaliado como moderado.

Quanto ao terceiro objetivo de analisar a relação entre modernidade organizacional e o comprometimento organizacional, foi verificado no modelo validado que esta relação se faz presente para o comprometimento afetivo e o normativo, mas apesar de positiva, para o comprometimento instrumental, não se mostrou significativa.

\section{CONSIDERAÇÕES FINAIS}

Em linhas gerais, voltando-se para a natureza hibrida das sociedades de economia mista pesquisadas, que devem manter-se competitivas tais como as organizações privadas, ao mesmo tempo em que transmitem maior segurança e estabilidade ao seu corpo funcional, verificou-se que os empregados públicos percebem o direcionamento estratégico e a identidade institucional destas organizações, porém reconhecem que ainda há o que se evoluir nas práticas de gestão de pessoas.

Como limitação desta pesquisa tem-se a representatividade da amostra, no que ser refere ao contexto da percepção de todos os colaboradores das organizações pesquisadas, tendo em vista que a pesquisa manteve o foco na percepção dos empregados públicos, não contemplando os colaboradores terceirizados e exclusivamente comissionados que também compõe o quadro geral de pessoas das organizações.

Ressalta-se o caráter inovador desta pesquisa, que requer estudos complementares utilizando os constructos estudados, buscando investigar como se dá esta relação em outras populações, como as organizações públicas com as características da administração direta, que não apresentam o caráter competitivo das economias mistas e asseguram ainda mais estabilidade aos servidores públicos e também em organizações privadas e altamente competitivas.

Por fim, o presente trabalho enfatiza a importância de se investigar melhor como as vertentes de modernidade, reconhecidas como boas práticas de gestão, podem estimular o desenvolvimento do comprometimento organizacional, garantindo o cumprimento da missão organizacional e fortalecendo a consecução dos objetivos desejados. 


\section{REFERÊNCIAS}

BABBIE, Earl. Métodos de pesquisa de survey. 3.ed. Belo Horizonte: UFMG, 2005.

BANDEIRA, M. L., MARQUES, A. L., \& VEIGA, R. T. As dimensões múltiplas do comprometimento organizacional: um estudo na ECT. RAC,[S. I.], v.4, n. 2, mai./ ago., 2000.

BASTOS, Antônio Virgílio Bittencourt. Comprometimento Organizacional: um balanço dos resultados e desafios que cercam essa tradição de pesquisa. Revista de Administração de Empresas,[S. I.], v. 33, n. 3, p. 52-64, 1993.

BORGES-ANDRADE, J. E. Conceituação e mensuração de comprometimento organizacional. Temas em psicologia.[S. I.], v.2 n.I p. 37-47, 1994.

CUSTÓDIO, Luciana Silva; SIQUEIRA, Carlos Alberto Antão; VIEGAS; Glauce, PINTO, Vânia Nepomuceno; SILVA, Rodrigo Pimenta da. Comprometimento Organizacional e Estratégias de Gestão de Pessoas: uma Análise das Experiências em Organizações Públicas Brasileiras. In: SEMINÁRIOS EM ADMINISTRAÇÃO - SEMEAD, FEA USP. 20I 3, Anais... São Paulo, 2013.

DEL MAESTRO FILHO, A. Modelo relacional entre modernização organizacional, práticas inovadoras de treinamento e satisfação no trabalho.2004. 28 If.Tese (Doutorado em administração) - Faculdade de Ciências Econômicas, Universidade Federal de Minas Gerais. Belo Horizonte, 2004.

DUTRA, Joel S.; HIPÓLITO, José Antonio M. Remuneração e recompensas. Rio de janeiro: Elsevier, 2012.

EBOLI, Marisa. P. Modernidade na gestão de bancos. 1996. Tese (Doutorado em administração) - Faculdade de Economia, Administração e Contabilidade, Universidade de São Paulo, São Paulo, 1996.

GIDDENS, Anthony. Modernidade e identidade. Rio de Janeiro: Zahar, 2002.

GIL. Antônio Carlos. Como elaborar projetos de pesquisa. São Paulo, Atlas, 2008.

GONZÁleZ, T. F.; GUILLÉN, M. Organizational commitment: a proposal for a widerethical conceptualization of 'normative commitment'. Journal of Business Ethics, [S. I.], v. 78, p. 40I-4I4, 2008.

HAIR JR, J.F., BLACK, W.C., BABIN, B.J., ANDERSON, R.E. \& TATHAM, R.L. (2009).Análisemultivariada de dados. Porto Alegre: Bookman.

MARÔCO, J. P. Análise de Equações Estruturais: Fundamentos teóricos, software e aplicações. ed. I. Pêro Pinheiro:Report. Number, 2010.

MEDEIROS, C. A. F; ALBUQUERQUE, M. S.; SIQUEIRA, M.; MARQUES, G. M. Comprometimento organizacional: o estado da arte da pesquisa no Brasil. Revista de Administração Contemporânea. [S. I.], v. 7, n. 4, p. 187-209, 2003.

MEDEIROS, C.A. F.; ENDERS,W.T.Validação do modelo de conceitualização de três componentes do comprometimento organizacional (Meyer e Allen, I99I). Revista de Administração Contemporânea, [S. I.], v.2, n.3, p.67-87, set./ dez. 1998.

MEYER, J. P.; ALLEN, N. J.A threecomponent conceptualization of organizational commitment. Hu- man Resource Management Review, [S. I.], v. I, p.6I-89, I99I.

MEYER, John P.; ALLEN, Natalie, J. Commitment in the workplace: theory, research, and application. London: Sage Publications, 1997.

MEYER, John P.; ALLEN, Natalie, J.; SMITH, C.A. (1993). Commitment to organizations and occupations: extension and test of a threecomponent conceptualization. Journal Psychology, [S. I.], 78, 538-55I.

MEYER, J. P.; HERSCOVITCH, L. Commitment in the Workplace: Toward a general Model. Human Resource Management Review, [S. I.], v. I I , p. 299-326, 200 I. MINTZBERG, Henry; LAMPEL, Joseph; QUINN, James Brian; GHOSHAL, Sumantra.O processo da estratégia: conceitos, contextos e casos selecionados. Porto Alegre:Artmed, 2007.

MOWDAY, R. T.; STEERS, R. M.; PORTER, L. W.The Measurement of Organizational Commitment. Journal of Vocational Behavior, [S. I.], v. 14, n.2, p. 224-247, 1979.

PINTO, M. P. C. (20II). Comprometimento organizacional: um estudo de suas relações com desempenho na carreira. 201 I. I44f. Dissertação. (Mestrado em Administração) - Universidade FUMEC, Belo Horizonte, $201 \mathrm{I}$.

RIBEIRO, J. A.; BASTOS, A. V. B. Comprometimento e Justiça Organizacional: Um Estudo de suas Relações com Recompensas Assimétricas. Revista Psicologia Ciência e Profissão. Brasília: Conselho Federal de Psicologia, [S. I.], 2010 , v. 30, n. I, p.4-21, 2010. REGO, A.. Comprometimento organizacional e ausência psicológica: 
afinal, quantas dimensões?.Revista de Administração de Empresas, [S. I.], v.43, n.4, p.25-35, 2003.

ROESCH, Sylvia Azevedo. Projetos de estágio e de pesquisa em administração: guia para estágios, trabalhos de conclusão, dissertações e estudos de caso. 3. ed., São Paulo:Atlas, 2006.

SÁ, M. A. D.; LEMOINE, C. O estilo de liderança como fator de comprometimento na empresa. In: ENCONTRO DAASSOCIAÇÃO DOS PROGRAMAS DE PÓSGRADUAÇÃO EM ADMINISTRAÇÃO, 1998, Foz do Iguaçu. Anais... Foz do Iguaçu, 1998.

SANT'ANNA, A. S. Competências individuais requeridas, mo- dernidade organizacional e satisfação no trabalho: uma análise de organizações mineiras sob a ótica de profissionais da área da administração.2002. 29If. Tese (Doutorado em administração), Faculdade de Administração, Universidade de Federal de Minas Gerais, Belo Horizonte, 2002.

SIQUEIRA, Mirlene M. M. Comprometimento Organizacional Afetivo, Calculativo e Normativo: Evidências Acerca da Validade Discriminante de Três Medidas Brasileiras. In: ENCONTRO DA ASSOCIAÇÃO DOS PROGRAMAS DE PÓS-GRADUAÇÃO EM ADMINISTRAÇÃO, 200I, Campinas. Anais... Campinas, $200 \mathrm{I}$.
SIQUEIRA, M. M. M. ; GOMIDE JR., S. Vínculo do Indivíduo com o Trabalho e com a Organização. In: Em BASTOS, B. V. A.; BORGES-ANDRADE, E. J.; ZANELLI, J. C. (Orgs.). Psicologia, Organizações e Trabalho no Brasil. Porto Alegre: Artmed, p. 300-328, 2004.

WORTHINGTON, R.;WHITTAKER, T. Scale development research. A content analysis and recommendations for best practices. The Counseling Psychologist. v. 34, n. 6, p. 806-838, 2006.

ZANELLI, José C.; SILVA, Narbal. Interação humana e gestão: a construção psicossocial das organizações de trabalho. São Paulo: Casa do Psicólogo, 2008. 